\section{Cave: Kaufpreiskontrolle bei der Praxisabgabe!}

\author{
Schlechte Nachrichten für Vertragsärzte in wegen Überversorgung \\ gesperrten Planungsbereichen: Der Zulassungsausschuss hat das \\ Recht, zu den finanziellen Konditionen des Praxisverkaufs ein Gut- \\ achten einzuholen und den Kaufpreis auf den Verkehrswert der \\ Praxis zu beschränken. Es ist daher besonders wichtig, die Praxis- \\ übergabe an einen Nachfolger langfristig vorzubereiten.
}

B ei der Übergabe einer Facharztpraxis an einen Nachfolger spricht der $\mathrm{Zu}$ lassungsausschuss ein gewichtiges Wort mit. Der Beschluss des Landessozialgerichtes Baden-Württemberg vom 22. November 2007 (Az.: L 5 KA 41/07 ER-B) sorgt hier bei den niedergelassenen Ärzten für Furore. Das Gericht hat in seiner rechtskräftigen Entscheidung den wirtschaftlichen Interessen der abgebenden Ärzte bei der Praxisübergabe in gesperrten Planungsbereichen enge Fesseln angelegt und die Position des ärztlichen Nachwuchses bei der Praxisübernahme gestärkt: „Die Einigkeit der Beteiligten über einen Kaufpreis vermag die Zulassungsgremien nicht zu binden."

\section{Verkehrwert der Praxis als Limit}

Die hier etablierte Preisaufsicht und Kaufpreiskontrolle durch den Zulassungsausschuss ist für die Fachärzte bei der Praxisübergabe eine brandgefährliche Sache. Das Gericht bezieht sich bei seiner Entscheidung auf die gesetzlichen Vorgaben in $\$ 103$ Abs. 4 SGB V. Danach habe der Zulassungsausschuss unter mehreren Bewerbern, die die abzugebende Praxis als

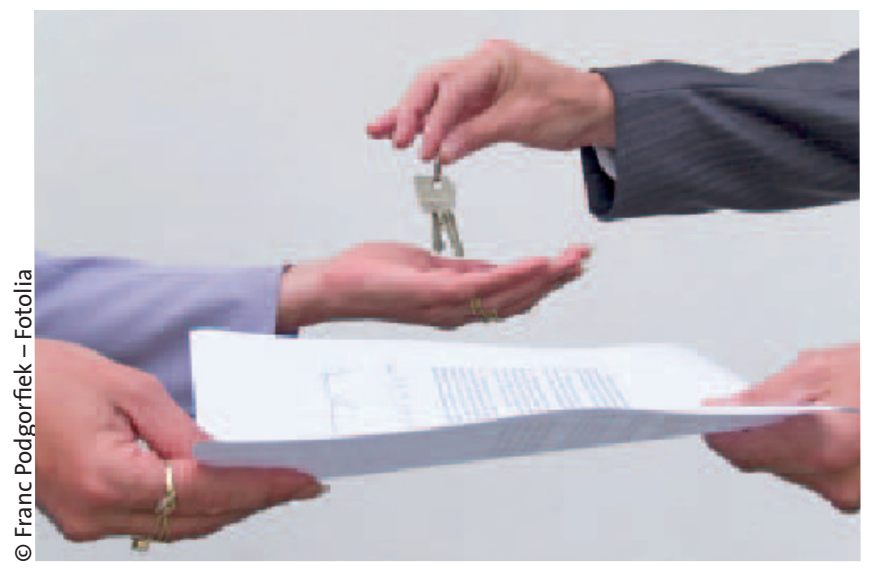

Nur weil Sie sich mit Ihrem Nachfolger einig sind, heißt das leider noch lange nicht, dass der Zulassungsausschuss der Praxisübergabe zustimmt.
Prozedere bei der Praxisübergabe Bei der Übergabe einer Vertragsarztpraxis in einem gesperrten Planungsbereich sind folgende Vorgaben $\mathrm{zu}$ beachten:

_ Die KV hat auf Antrag des Arztes bzw. seiner Erben den Vertragsarztsitz unverzüglich auszuschreiben.

— Die KV erstellt eine Liste der eingehenden Bewerbungen und stellt sie dem Zulassungsausschuss und dem Arzt bzw. seinen Erben zur Verfügung.

— Unter mehreren Bewerbern hat der Zulassungsausschuss den Nachfolger nach pflichtgemäßem Ermessen auszuwählen.

- Bei der Auswahl ist die berufliche Eignung, das Approbationsalter und die Dauer der ärztlichen Tätigkeit zu berücksichtigen.

_ Es ist auch zu berücksichtigen, ob der Bewerber der Ehegatte, ein Kind, ein angestellter Arzt des bisherigen Vertragsarztes oder ein Vertragsarzt ist, mit dem die Praxis bisher gemeinschaftlich ausgeübt wurde.

— Die wirtschaftlichen Interessen des ausscheidenden Vertragsarztes sind nur insoweit zu berücksichtigen, als der Kaufpreis die Höhe des Verkehrswertes nicht übersteigt ( $\$ 103$ Abs. 4 SGB V).

kehrswert entsprechenden Praxisverkaufspreis bezieht. Die Vertragsfreiheit der Vertragsärzte, die aus der Versorgung ausscheiden und ihre Praxis an einen Nachfolger verkaufen, wird damit deutlich eingeschränkt.

\section{Gebot der Fairness missachtet?}

Das Landessozialgericht betont ausdrücklich, es sei für die abgebenden Ärzte kein rechtlicher Nachteil darin zu sehen, dass sie aus der Knappheit der zur Verfügung stehenden Arztsitze kein Kapital schlagen könnten. Dies wäre nämlich der Fall, wenn ihre Praxis zu einem Preis oberhalb des Verkehrswertes verkauft würde. Denn der den Verkehrswert übersteigende Betrag beruhe nicht auf dem durch ihre Leistung begründeten Wert ihrer Praxis, sondern auf der als Folge von Zulassungsbeschränkungen administrativ verordneten Knappheit von Arztsitzen. red 